Hydrology and Earth System Sciences, 1, 205-212 (1997) C EGS

\title{
The aggregate description of semi-arid vegetation with precipitation-generated soil moisture heterogeneity
}

\author{
Cary B. White, Paul R. Houser, Altaf M. Arain, Zong-Liang Yang, Kamran Syed, and W. James \\ Shuttleworth \\ Department of Hydrology and Water Resources, The University of Arizona, Tucson, AZ 85721 USA
}

\section{Abstract}

\begin{abstract}
Meteorological measurements in the Walnut Gulch catchment in Arizona were used to synthesize a distributed, hourly-average time series of data across a 26.9 by $12.5 \mathrm{~km}$ area with a grid resolution of $480 \mathrm{~m}$ for a continuous 18-month period which included two seasons of monsoonal rainfall. Coupled surface-atmosphere model runs established the acceptability (for modelling purposes) of assuming uniformity in all meteorological variables other than rainfall. Rainfall was interpolated onto the grid from an array of 82 recording rain gauges. These meteorological data were used as forcing variables for an equivalent array of stand-alone Biosphere-Atmosphere Transfer Scheme (BATS) models to describe the evolution of soil moisture and surface energy fluxes in response to the prevalent, heterogeneous pattern of convective precipitation. The calculated area-average behaviour was compared with that given by a single aggregate BATS simulation forced with area-average meteorological data. Heterogeneous rainfall gives rise to significant but partly compensating differences in the transpiration and the intercepted rainfall components of total evaporation during rain storms. However, the calculated area-average surface energy fluxes given by the two simulations in rain-free conditions with strong heterogeneity in soil moisture were always close to identical, a result which is independent of whether default or site-specific vegetation and soil parameters were used. Because the spatial variability in soil moisture throughout the catchment has the same order of magnitude as the amount of rain falling in a typical convective storm (commonly $10 \%$ of the vegetation's root zone saturation) in a semi-arid environment, non-linearity in the relationship between transpiration and the soil moisture available to the vegetation has limited influence on area-average surface fluxes.
\end{abstract}

\section{Introduction}

This research note addresses the question, 'In the extreme case of the semi-arid environment subject to convective rainfall, are the ensuing real patterns of soil moisture such that they have significant impact on the area-average description of vegetation in meteorological models?' It is best read as a sequel to Arain et al. (1996).

Arain $e t$ al. investigated the adequacy of simple rules for defining the effective, area-average (or aggregate) value of the vegetation-related parameters required to specify surface-atmosphere interactions for heterogeneous mixes of vegetation covers. They used data from the First International Satellite Land Surface Climatology Field Experiment (FIFE; Sellers et al., 1988) to validate and initiate the BATS-ABL coupled model of interac- tions between land surfaces and the atmospheric boundary layer (Arain et al., 1996). In most conditions they found that so-called aggregation rules (Shuttleworth, 1992) can provide area-average values of vegetation parameters which, when applied within the BiosphereAtmosphere Transfer Scheme (BATS; Dickinson et al., 1986), calculate values of surface fluxes that are acceptably similar to those calculated with explicit recognition of different patches of vegetation cover in the coupled model.

As a side-issue in their paper, Arain et al. (1996) discovered that when they included a significant proportion of irrigated crops amongst heterogeneous vegetation in an otherwise dry landscape, the performance of the hypothetical aggregation rules was compromised. This result 
is explained by the non-linear response of vegetation to changing soil moisture in the BATS and, it is assumed, in nature as well-see Arain et al. (1996) for greater detail.

An analysis of satellite-derived land cover classes shows that the proportion of irrigated land falling within an individual grid square used in meteorological models is rarely greater than $10 \%$ in the USA. (The USA is the only region for which such data sets are readily available at this time.) Moreover, coupled modelling studies using the BATS-ABL show that including irrigated vegetation in this proportion still allows the use of aggregation rules with acceptable accuracy in the simulated areaaverage fluxes. Hence, the presence of patches of artificially wetted (irrigated) soil is not a serious issue.

However, Arain et al. (1996) suggested that in certain circumstances extreme differences in soil moisture might occur naturally and they recommended that a study be made to determine if poor aggregation rule performance exists in natural situations. This note explores this specific issue for the deliberately extreme case of soil moisture heterogeneity resulting from intermittent localized convective rain falling in a semi-arid region of the southwestern USA.

\section{Field Data}

The data used in this study are from the Walnut Gulch Experimental Watershed $\left(31^{\circ} 43^{\prime} \mathrm{N}, 110^{\circ} 00^{\prime} \mathrm{W}\right)$, which is located $120 \mathrm{~km}$ southeast of Tucson, Arizona, and which comprises the upper $150 \mathrm{~km}^{2}$ of the Walnut Gulch drainage basin (see Fig. 1). Here, soil types range from clays and silts to well-cemented boulder conglomerates (Renard et al., 1993), with gravelly and sandy loam sur- face textures containing an average of $30 \%$ rock and little organic matter (Kustas and Goodrich, 1994). The topography comprises gently rolling hills incised by rather steep drainage channels. The mixed grass-brush rangeland vegetation, which is typical of southeastern Arizona and southwestern New Mexico, ranges from 20 to $60 \%$ in coverage.

The catchment receives $250-500 \mathrm{~mm}$ of precipitation annually, two-thirds of it falling as convective precipitation during a summer monsoon season encompassing the months of July through to mid-September. The balance of precipitation falls mainly during winter frontal storms of Pacific origin. The monsoonal precipitation is usually from high-intensity convective thunderstorms of limited areal extent. The average run-off in the ephemeral streams is small $(\sim 5 \%)$ and of short duration, which implies that one-dimensional models, like the BATS, can provide a reasonably realistic description of this region's surface-atmosphere interactions. The 85 recording rain gauges which are currently maintained in and around the catchment-an average of one rain gauge per $1.76 \mathrm{~km}^{2}$, along with 11 runoff measuring flumes, and two sets of weather and energy flux measuring stations are indicated in Fig. 1. Rainfall and runoff are recorded continuously on analogue charts and digitized into breakpoint data. Practical temporal resolution of the rainfall and runoff data is $\pm 5 \mathrm{~min}$, and $\pm 2 \mathrm{~min}$., respectively (Renard et al., 1993; Kustas and Goodrich, 1994). Weather and energy flux measuring stations are recorded on data loggers every 20 minutes (Stannard et al., 1994; Kustas and Goodrich, 1994). For additional information on the Walnut Gulch catchment and the field systems deployed there see Kustas et al. (1991), (1994a), (1994b), (1994c), Kustas and Goodrich (1994), Stannard et al. (1994),

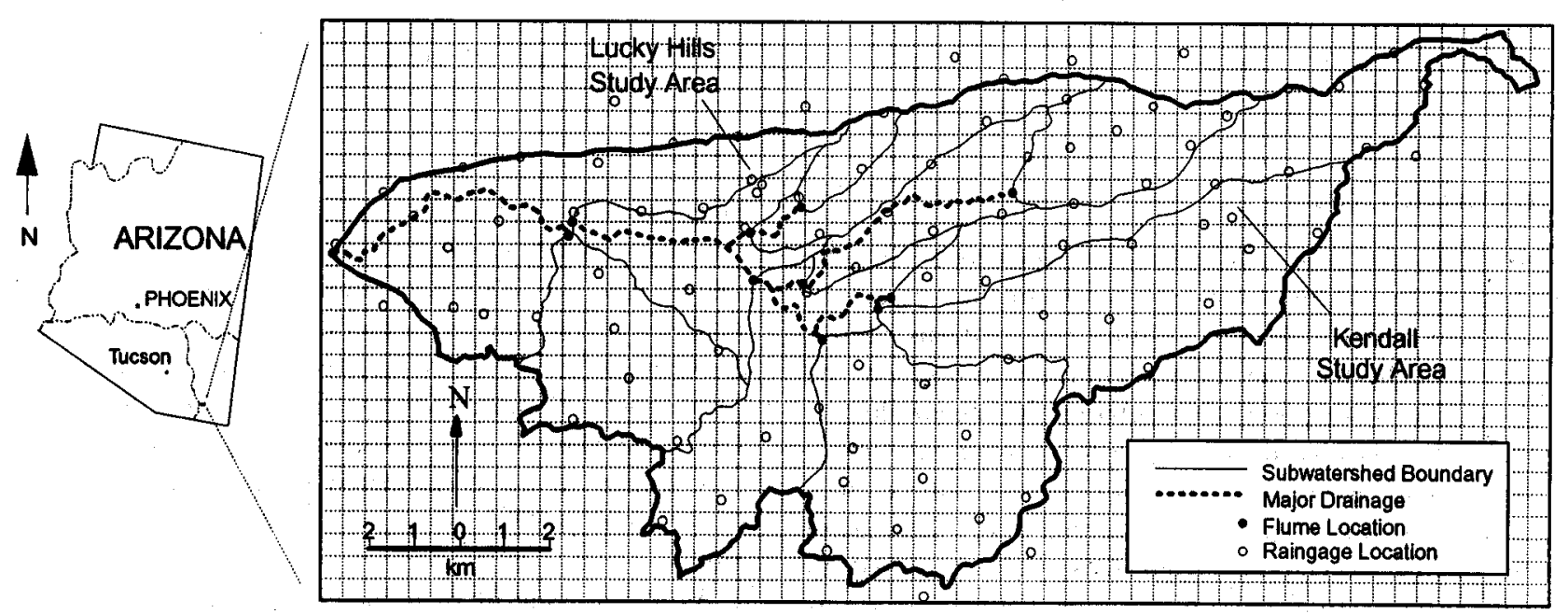

Fig. 1 The area described by the distributed array of stand-alone BATS models which includes the Walnut Gulch catchment in Arizona. The figure shows the catchment boundary, the location of rain gauges, flumes and the Kendall and Lucky Hills micrometeorological stations. 
Moran et al. (1994), Humes et al. (1994), Weltz et al. (1994), Menenti and Ritchie (1994) and Hipps et al. (1994).

\section{SYNTHESIS OF DISTRIBUTED DATA ARRAYS}

This modelling study commenced on July 16, 1990 and continued through to December 31, 1991. It therefore included two seasons of monsoon rainfall, the first season being wetter than average and the second season drier than average. The modelling strategy (described below) requires a two-dimensional, distributed array of hourlyaverage near-surface meteorological forcing variables, for the stand-alone version of the BATS for the 18-month study period. These data were synthesized from available measurements and projected on to a 56 column by 26 row array that covers the Walnut Gulch catchment at a $480 \mathrm{~m}$ grid resolution (Figure 1). The 651 grid squares, which are located within the boundary of the Walnut Gulch catchment, are those for which model comparisons were made in this study.

Comparisons between the meteorological observations at the two weather and energy flux measuring stations showed that, when it was not raining, the inter-site differences in solar radiation, temperature and vapour pressure deficit were low (typically less than $20 \mathrm{Wm}^{-2}, 1^{\circ} \mathrm{C}$, and $0.14 \mathrm{kPa}$ respectively), even when the difference in the observed soil moisture at these sites was at a maximum. Larger, short-term differences were observed (particularly in temperature and vapour pressure deficit) while it was raining, if the intensity and, in particular, the timing of rainfall differed between the two sites. Large short term differences in solar radiation were typical on cloudy days. However, model sensitivity tests, using the two observed time series of weather variables as alternate forcings, demonstrated that the overall results of this study are not sensitive to this meteorological variability. This is because the periods for which there were significant differences in the meteorological variables between the two sites is a small proportion of the time for which model integrations were made. Moreover, studies with the BATS-ABL coupled model (described later) show that area-average surface fluxes have little sensitivity to atmospheric advection that might have been generated by the most extreme observed differences in soil moisture.

In consequence of the just-described observations and modelling results, it is appropriate to assume that the values of incoming solar radiation, near-surface air temperature and vapour pressure deficit required by the stand-alone version of the BATS are, in effect, constant across the 26.9 by $12.5 \mathrm{~km}$ study area. For reasons of data consistency, the preferred values of meteorological forcing variables applied during modelling were those from the Kendall micrometeorological station (Fig. 1). However, for about $1 \%$ of the time, data were missing from this site so data from Lucky Hills were substituted, and for a few brief periods (less than 1\% of the time) when neither station was operational, it was necessary to use data from a nearby Fort Huachuca meteorological station. Tests made at times when data from both Walnut Gulch and Fort Huachuca were available confirmed that differences in these forcings were insignificant for modelling purposes.

Distributed precipitation fields were provided by interpolation from the rain gauge network. To ensure consistency, interpolation was made from the 82 gauges for which continuous rainfall data were available for the whole study period. Raw rain gauge data were digitized from analogue charts and then converted into an hourly time series for the 18-month study period. Previous studies with this rain gauge network (Haider, 1994) have demonstrated that the multiquadric-biharmonic technique is the preferred method of interpolating precipitation because it combines practicality with acceptable accuracy. An hourly time series of precipitation data was synthesized for each node in the distributed data grid by applying this technique at each hour of the study period to interpolate the rain gauge data to the equivalent grid location.

\section{BATS MODEL CALIBRATION}

To test the sensitivity of the specific aggregated results to the vegetation parameters in the BATS, the aggregate modelling tests (described later) were performed using both the default BATS semi-arid vegetation parameters and the site-specific parameter values observed at the Walnut Gulch study site.

Performance of these two parameter sets was evaluated by comparing the resulting-modelled surface fluxes with the measurements at the two observation sites. However, the value of this comparison was restricted by known weaknesses in the flux measuring instruments used at these sites. The observation of sensible heat flux was made at a height of $9 \mathrm{~m}$, using the eddy correlation method with a single 'Gill' propeller to measure the vertical wind velocity (Stannard et al., 1994). A previous comparison with relevant energy- and water-balance data (Williams, 1996) indicates that the routine use of this wind sensor results, on average, in about a $30 \%$ undermeasurement of sensible heat flux. Therefore, a fixed correction of this size was applied to the measured sensible heat flux prior to its use in the energy budget, to calculate latent heat flux for the purpose of comparison with model calculations.

The standard BATS parameters appropriate to the Walnut Gulch study site corresponded to surface cover/vegetation class number 11, the semi-desert default (from the 18 available classes), soil textual class 3 (from 12 textural classes ranging from sand [1] to clay [12]), and soil colour class 2 (from the 8 available colour 
classes ranging from light [1] to dark [8]) (Dickinson et al., 1986). Simulations using these parameters provided poor agreement with observed surface energy fluxes, both in terms of the overall magnitude of the fluxes (latent heat fluxes being on average underestimated by $58 \%$, while sensible heat fluxes were overestimated by $33 \%$ ), and in terms of the modelled daily pattern (the model calculated that latent heat fluxes fell rapidly after an early morning peak, while observations suggested a more uniform daily pattern).

Selection of site-specific parameters was largely based on the literature, much of which resulted from the Monsoon-90 field campaign which was held in the Walnut Gulch catchment from July 23 to August 10, 1990, and which has been documented extensively (e.g. Kustas et al., 1991, 1994a, 1994b, 1994c, Kustas and Goodrich, 1994, Stannard et al., 1994, Moran et al., 1994, Humes et al., 1994, Weltz et al., 1994, Menenti and Ritchie, 1994, Hipps et al., 1994). These sources allowed the confident specification of many BATS vegetation parameters (including percentage vegetation cover, roughness length, zero-plane displacement height, albedo, and maximum and minimum leaf area indices), and many soil parameters (including porosity, saturated hydraulic conductivity, and wet and dry soil albedos). In addition, a prior modelling study carried out at a Sonoran Desert site near Tucson, Arizona (Unland et al., 1996) suggested that two other parameters (the minimum stomatal resistance of the vegetation and the fraction of water extracted from the upper soil layer) require revision if the BATS is to provide realistic simulation of semi-arid vegetation. The values of these two parameters were therefore determined by a simple optimization process, against the observed surface energy fluxes in an analogous way to Unland et al. (1996).

Use of the revised, site-specific parameters greatly enhanced the quality of the comparison between the BATS modelled fluxes and observed fluxes, resulting in correlation coefficients of $0.875,0.912$, and 0.970 and root mean squared errors of $41.7 \mathrm{Wm}^{-2}, 50.8 \mathrm{Wm}^{-2}$, and $20.3 \mathrm{Wm}^{-2}$ for latent, sensible and ground heat flux respectively.

\section{Modelling Studies}

This project explored two modelling issues. The first was to check the validity of assuming uniform meteorology (apart from precipitation) across the Walnut Gulch catchment, while the second appraised the impact of heterogeneous precipitation on vegetation-atmosphere interactions.

\section{COUPLED MODELLING TESTS}

The BATS-ABL model was used to investigate the significance of possible patch-to-patch atmospheric advection in the presence of extreme soil moisture heterogeneity observed across the study site. An initial run was made using the distributed array of stand-alone BATS models forced with the distributed array of meteorological data (see below) to determine the most extreme differences in modelled soil moisture status in the catchment. The soil moisture status and soil and vegetation temperatures for the two most extreme elements in the model array were selected and used as initial values for moist and dry patches in BATS-ABL, while the area-average meteorology at the time these extreme values occurred was used to initiate the atmospheric variables in that model (Arain, 1994), Arain et al., 1996).

The BATS-ABL was run from these initial conditions with a modelled domain size of $2000 \mathrm{~m}$ and with alternate vegetation patches (with wet and dry soil) each 1000 $\mathrm{m}$ wide (Arain et al., 1996). On the basis of the surfaceatmosphere interaction simulated with the BATS-ABL, area-average values of the surface exchanges and of the near-surface meteorological variables at $2 \mathrm{~m}$ were calculated across the modelled domain. A separate calculation of the area-average surface exchanges was then made, with the area-average value of the meteorological variables at $2 \mathrm{~m}$ used as forcing variables (rather than the spatially varying values of forcing variables that had been modelled to occur at this height in the BATS-ABL run). In this way, an assessment could be made of the acceptability of assuming a uniform meteorology (in all but precipitation) across the Walnut Gulch catchment in the distributed array model runs. The results of this coupled modelling study were reassuring in that the calculated area-average fluxes, given by the BATS-ABL (which acknowledge spatial variability in near-surface meteorology coupled to variability in soil moisture), agreed with those calculated using an enforced uniformity in near surface meteorology to within $11.5 \%, 8.6 \%$ and $7.1 \%$ for latent, sensible and ground heat flux respectively in these conditions of most extreme soil moisture difference.

\section{AGGREGATION MODELLING STUDIES}

Two stand-alone BATS modelling studies were used to assess the impact of heterogeneous precipitation on vegetation-atmosphere interactions. An individual (aggregate) BATS model and a distributed array of single point BATS models were created and parameterized identically over the Walnut Gulch catchment. The distributed BATS model was driven with the spatially distributed meteorological forcing data derived as described above, while the aggregate BATS model was forced with meteorological data which was the area-average of that used for the distributed array for each hour. (Recall that, in practice, precipitation is the only variable considered to have significant spatial heterogeneity).

The calculated surface exchanges for the array of single point BATS models were averaged and compared 
LATENT HEAT FLUX

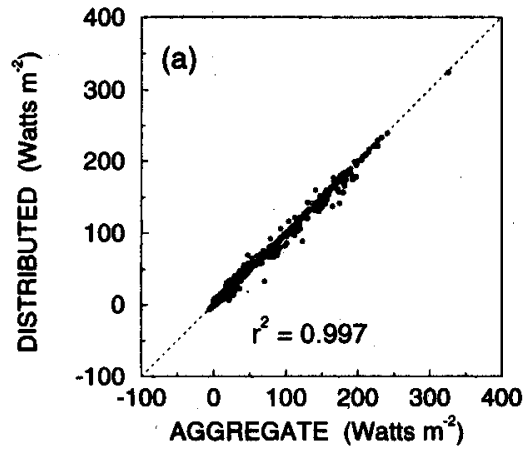

SENSIBLE HEAT FLUX

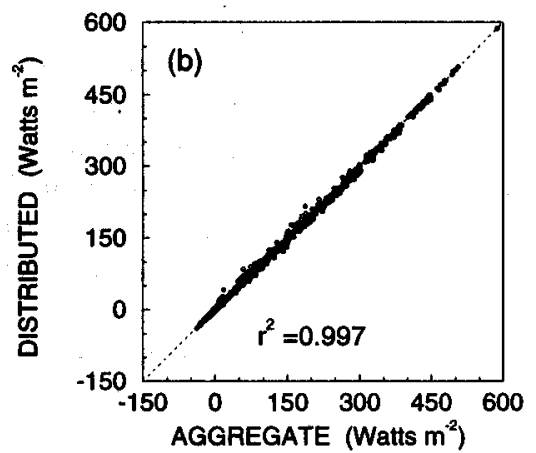

GROUND HEAT FLUX

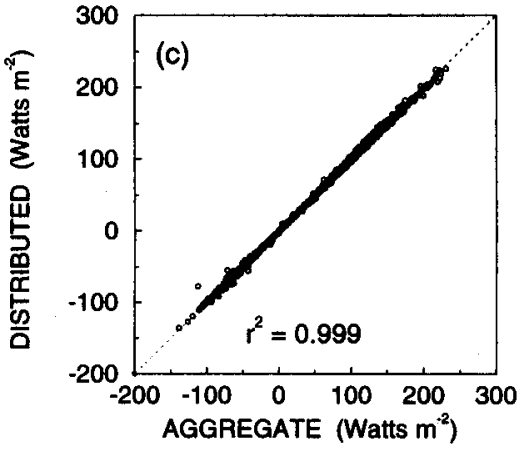

Fig. 2 Comparison betmeen the hourly-average (a) the latent-heat flux; (b) sensible-heat flux; and (c) ground heat flux as calculated by the single, aggregate BATS model forced with area-average meteorological data and the distributed array of BATS models forced with distributed data for all rain-free hours in the 18 month study period

to the output from the aggregate BATS model which, it was hypothesized, provided an adequate area-average description. In this way, the area-average interaction with the realistic representation of precipitation-induced heterogeneity in soil moisture can be compared with that given when heterogeneity is neglected in the modelling process. If the two outputs disagree with one another, then failure of aggregation rules (analogous to that which Arain $e t$ al. (1996) reported as possible with patches of irrigated agriculture) can be deemed to have occurred in these albeit extreme, but nonetheless natural, conditions.

The results indicate no evidence of significant aggregation rule failure with naturally-occurring differences in soil moisture. Modelling results are presented here only for runs using the site-specific BATS parameters but simulations were also made with the BATS default parameters (see above). Although the area-average surface energy fluxes, calculated with the default parameterization in both the aggregate and the distributed array BATS models, differed from the equivalent runs using the site-specific parameters, none of the conclusions given below is affected because these conclusions are based on the difference between aggregate and distributed array runs made with the same set of model parameters.

Figure 2 shows a comparison between the calculated latent heat, sensible heat and ground heat fluxes given by the aggregate BATS model and those given by the distributed array of BATS models for hours when there was no intercepted water on the vegetation canopy during the 18 month study. Clearly surface energy fluxes agree extremely well, to within a few $10 \mathrm{~s} \mathrm{Wm}^{-2}$-this being the criterion for success adopted by Arain et al. (1996).

Notwithstanding this success in rain-free conditions, an interesting side-effect of spatial variability in precipitation is apparent in this study, and is related to the interception of rainfall by the vegetation canopy. When the rain falling in a storm covers a large proportion (approximately $60 \%$ or more) of the study area modelled there is an inconsequential difference between the calculated components of evapouration for simulations made with the aggregate BATS model and the dis-
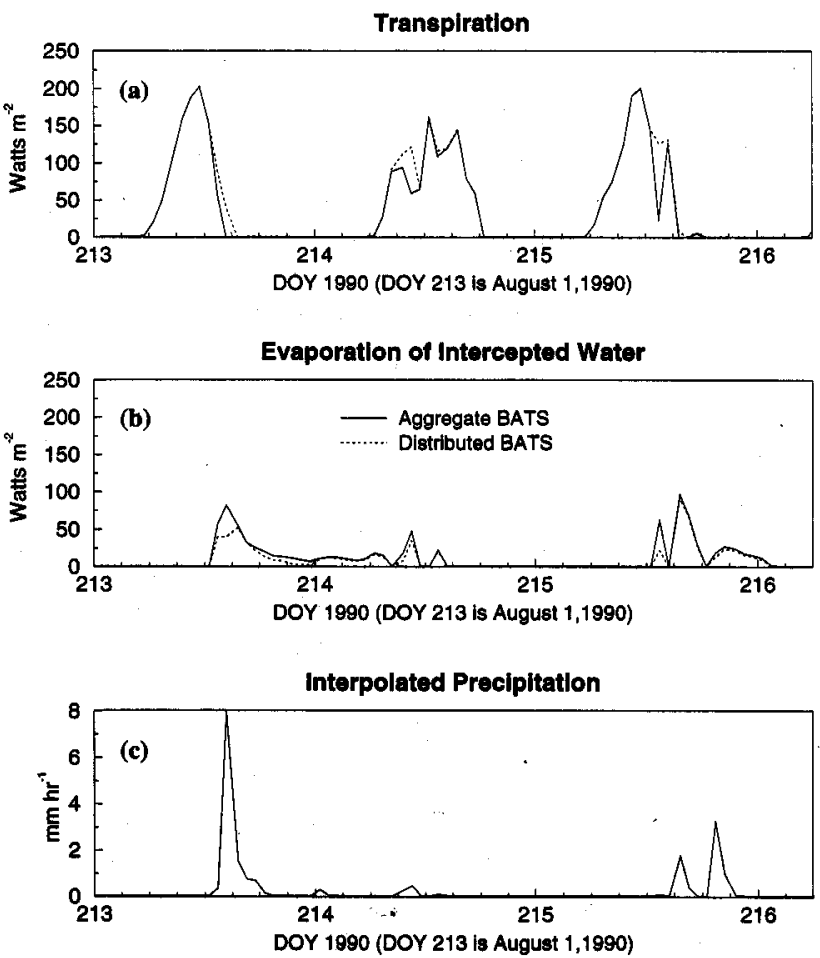

Fig. 3 Time series of calculated rates of (a) transpiration, (b) evaporation of intercepted water as given by the single, aggregate $B A T S$ model forced with area-average meteorological data (full line) and the distributed array of BATS models forced with distributed data (broken line) and (c) the interpolated precipitation from (DOY) day of year 213 to 215 of 1990 (August 1-August 3, 1990). There mere 7 localized rain storms during this period. 
Table 1. Modelled Water Balance Components for the Aggregate and Distributed $B A T S$ models using site-specific parameters.

Modelled Water Balance from July 16, 1990-December 31, 1991 (534 Day Model Run)

\begin{tabular}{lccr}
\hline $\begin{array}{l}\text { Cumulative water } \\
\text { balance component }\end{array}$ & $\begin{array}{c}\text { Aggregate } \\
\text { model } \\
(\mathrm{mm})\end{array}$ & $\begin{array}{c}\text { Distributed } \\
\text { model } \\
(\mathrm{mm})\end{array}$ & \% Difference* \\
\hline Evaporation flux & 446.27 & 467.29 & $0.22 \%$ \\
Precipitation & 426.46 & 426.34 & $-0.03 \%$ \\
Runoff & 21.33 & 20.33 & $-4.92 \%$ \\
$\Delta$ Storage from soil & -54.53 & -55.05 & $0.99 \%$ \\
moisture & & & \\
Transpiration & 359.41 & 366.05 & $1.81 \%$ \\
Interception & 25.91 & 19.51 & $-32.80 \%$ \\
Soil evaporation & 73.62 & 74.59 & $1.30 \%$ \\
\hline
\end{tabular}

Water balance closure

\begin{tabular}{lccc}
\hline & $\begin{array}{c}\Sigma \text { Input } \\
(\mathrm{mm})\end{array}$ & $\begin{array}{c}\Sigma \text { Output } \\
(\mathrm{mm})\end{array}$ & $\Sigma$ in/ $\Sigma$ Out \\
\hline Aggregate & 459.66 & 466.27 & $98.6 \%$ \\
Distributed & 461.06 & 467.29 & $98.7 \%$ \\
\hline
\end{tabular}

* $[$ (Distributed - Aggregate $) /$ Distributed $] \times 100 \%$

tributed array of BATS model. However, when storms of limited extent occur, this is not the case. Figure 3 shows an example of the area-average, model-calculated evaporation flux for the study area that originate (a) as transpiration, and (b) as the evaporation of intercepted water, along with (c) the interpolated rainfall for 3 days when there were 7 short storms, 3 of which covered approximately $25 \%$ of the modelled area whereas the remaining 4 covered less than $10 \%$ of the modelled area. Inspection of Fig. 3 reveals that localized storms of this type give rise to differences in the modelled area-average rate of evaporation of intercepted water between the aggregate and distributed array models, which can be as large as $30-50 \%$ for short periods.

This difference arises because the aggregate model rainfall is (wrongly) assumed to be equally distributed across the modelled area, so all elements in the grid contribute to the net interception loss, and its modelled interception rate is therefore higher. At the same time, there is (in part) a compensating difference in the area-average transpiration flux, because it is suppressed for the whole study area and not just for the rained-on portion. However, the compensation between these two components of evaporation loss is not perfect and, in general, the erroneous enhancement of calculated interception loss for the aggregate BATS model slightly exceeds the erroneous reduction in the calculated transpiration loss during the storm. Consequently, more water evaporates and less rain infiltrates during storms, causing the modelled soil moisture and transpiration to be slightly less on rain-free days. This small reduction in inter-storm, area-average transpiration is $1.8 \%$ as modelled. Table 1 lists this difference, as well as the differences between the cumulative water balance components for both simulations.

Bare soil evaporation rate is known significantly to enhance evaporation rates for sparse, semi-arid crops for a few days after each rain storm (Gash et al, 1991). The presence of this enhanced soil evaporation, which is restricted to the rained-on portion of the landscape, could generate differences between calculations made with the distributed and aggregate models for reasons which are essentially identical to those for the interception process described above. Such short-term differences can occur for storms which cover only part of the modelled area, but the cumulative effect over the whole study period of differences in soil evaporation calculated with the two models is small (Table 1).

\section{Discussion and Conclusions}

On the basis of the above comments, it is clear that heterogeneous rainfall can result in a poor description of short-term evaporation rates during and immediately after rainfall because the description of the rainfall interception and soil evaporation processes is imperfect in a one-dimensional, aggregate representation. This feature has been recognized for some time, (Shuttleworth, 1988). However, in the case of semi-arid regions, where there is little runoff and where water availability is the limiting control on evaporation, maintaining the water balance necessarily requires that modelled transpiration is reduced between rain storms to compensate for this additional within-storm loss due to the evaporation of intercepted rain. In the case of soil evaporation, there is similar compensation for patches of bare soil, between greater soil evaporation calculated with the distributed model immediately after rainfall and reduced soil evaporation calculated between storms. Such compensation between the separate components of total evaporation will not necessarily occur in regions where evaporation rates are energy limited and runoff is plentiful.

Notwithstanding this last mentioned complication, the primary focus of the present study was to investigate whether realistic patterns of soil moisture have significant impact on the area-average description of vegetation in meteorological models in the extreme case of a semi-arid environment subject to intermittent but intense convective rainfall. The results are definitive in this respect. In rain-free conditions but with natural, rain-induced, heterogeneous soil moisture, the difference between the calculated surface energy fluxes given by a single, aggregate BATS model and that given by a distributed array of BATS models is very small indeed.

The basic reason for this is that the amount of rain in 
an individual precipitation event is always a fairly small proportion of the total amount of water that can be stored within the rooting zone of the simulated vegetation. In this study, the area-average soil moisture stored in the rooting zone varies with season: typically, the soil moisture store is about half full during the monsoon season, and close to empty after an extended dry period. However, because local convective storms occur randomly in space, spatial variations in available soil moisture across the landscape at any time have the same order of magnitude as the amount of rain in one typical rainfall event. Convective rain storms can be heavy and localized in this environment - the largest storm observed at any grid point in the modelled array during the study period was about $50 \mathrm{~mm}$, for instance, but the amount of water that can be stored in the rooting zone of the vegetation $(336 \mathrm{~mm})$ is large in comparison with this. Hence, at any time, only about $10 \%$ of the non-linear relationship between soil moisture and evaporation is being sampled within a given soil moisture pattern, so that the non-linear relationship can be considered approximately linear over this small, sampled range. Given that this is the case in this extreme semi-arid situation, it is likely that it is more generally true elsewhere.

\section{Acknowledgement}

The USDA-ARS Southwest Watershed Research Center is gratefully acknowledged for providing the data from the Walnut Gulch Experimental Watershed utilized in this study. The research described in this paper was carried out under the NASA Terrestrial Ecology Program (Grant number NAG-5 3854). Paul Houser was supported under the NASA Hydrology Program (Grant number NAGW-4165) and Kamran Syed under the NASA-EOS Interdisciplinary Research Program (Grant number NASA IDP-88-086), while Altaf $M$. Arain was a NASA Global Change Research Fellow (Grant nymber NGT-30303).

\section{References}

Arain, A.M., 1994. Spatial aggregation of vegetation parameters in a coupled land surface-atmosphere model. M.S. Thesis, The University of Arizona, Tucson, USA. $150 \mathrm{pp}$.

Arain, A.M., Michaud J., Shuttleworth, W. J., and Dolman, A. J., 1996. Testing of vegetation parameter aggregation rules applicable to the Biosphere-Atmosphere Transfer Scheme $(B A T S)$ and the FIFE site. J. Hydrol., 177:1-22.

Dickinson, R.E., Henderson-Sellers, A., Kennedy, P.J., and Wilson, M.F., 1986. Biosphere-Atmosphere Transfer Scheme (BATS) for the NCAR Community Climate Model. Technical Note NCAR/TN-275+STR. National Center for Atmospheric Research, Boulder, CO. 69 pp.

Gash, J.H.C., Wallace, J.S., Lloyd, C.R, Dolman, A.J., Sivakumar, M.V.K. and Renard, C., 1991, Measurements of evaporation from fallow Sahelian savannah at the start of the dry season, Quart. J. R. Meteorol. Soc., 117, 746-760.

Haider, S.K., 1994. Spatial storm characteristics and basin response. M.S. Thesis, The University of Arizona, Tucson, USA. $261 \mathrm{pp}$.

Hipps, L.E. and Siatek, E., 1994. Interactions between regional surface fluxes and the atmospheric boundary layer over a heterogeneous watershed. Water Resour. Res, 30(5): 13871392.

Humes, K.S., Kustas, W.P., and Moran, M.S., 1994. Use of remote sensing and reference site measurements to estimate instantaneous surface energy balance components over a semi-arid rangeland and watershed. Water Resour. Res., 30(5): 1363-1373.

Kustas and Goodrich, 1994. Preface. Water Resour. Res, 30(5): 1211-1225.

Kustas, W.P., Goodrich, D.C., Moran, M.S., Amer, A.M., Bach, L.B., Blanford, J.H., Chehbouni, A., Claassen, H., Clements, W.E., Doraiswamy, P.C., Dubois, P., Clarke, T.R., Daughtry, C.S.T., Gellman, D.I., Grant, T.A., Hipps, L.E., Huete, A.R., Humes, K.S., Jackson, T.J., Keefer, T.O., Nichols, W.D., Parry, R., Perry, E.M., Pinker, R.T., Pinter, P.J., Qi, J., Riggs, A.C., Schmugge, T.J., Shutko, A.M., Stannard, D.I., Swiatek, E., van Leeuwen, J.D., van Syl, J., Vidal, A., and Weltz, M.A., 1991. An interdisciplinary field study of the energy and water fluxes in the atmosphere-biosphere system over semi-arid rangelands: Description and preliminary results. Bull. Am. Meteor. Soc., 72: 1683-1705.

Kustas, W.P, Blanford, J.H., Stannard, D.I., Daughtry, C.S.J., Nichols, W.D., and Weltz, M.A., 1994a. Local energy flux estimates for unstable conditions using variance data in semiarid rangelands. Water Resour. Res., 30(5): 1351-1361.

Kustas, W.P., Moran, M.S., Humes, K.S., Stannard, D.I., Pinter, P.J., Hipps, L.E., Swiatek, E., and Goodrich, D.C., 1994b. Surface energy balance estimates at local and regional scales using optical remote sensing from an aircraft platform and atmospheric data collected over semi-arid rangelands. Water Resour. Res., 30(5): 1241-1260.

Kustas, W.P., Schmugge, T.J. , Hume, K.S., Jackson, T.J., Parry, R., Weltz, M.A., and Moran, S., 1994c. Relationships between evaporative fraction and remotely sensed vegetation index and microwave brightness temperature for semiarid rangelands. J. Appl. Meteorol., 32(12): 1781-1790.

Menenti, M. and Ritchie, J.C., 1994. Estimation of effective aerodynamic roughness of Walnut Gulch Watershed with laser altimeter measurements. Water Resour. Res., 30(5): 1329-1337.

Moran, M.S., Clarke, T.R., Kustas, W.P., Weltz, M. , and Amer, S.A. , 1994. Evaluation of hydrologic parameters in a semi-arid rangeland using remotely sensed spectral data. Water Resour. Res., 30(5): 1287-1297.

Renard, K.G., Lane, L.J., Simanton, J.R., Emmerich, W.E., Stone, J.J., Weltz, M.A., Goodrich, D.C., and Yakowitz, D.S., 1993. Agricultural impacts in an arid environment: Walnut Gulch studies. Hydrol. Sci. and Tech., 9(1-4): 145190.

Sellers P.J., Hall, F.G., Asrar, G., Strebel, D.E., and Murphy, R.E., 1988. The first ISLSCP field experiment (FIFE). Bull. Am. Meteor. Soc., 69: 22-27

Shuttleworth, W.J., 1988. Macrohydrology-the new challenge for process hydrology. J. Hydrol., 100: 31-56.

Shuttleworth, W.J., 1992. The Modellion concept. Rev. Geophys., 29: 585-606. 
Stannard, D.I., Blanford, J.H., Kustas, W.P., Nichols, W.D., Amer, S.A., Schmugge, T.J. and Weltz, M.A., 1994. Interpretation of surface flux measurements in heterogeneous terrain during Monsoon '90. Water Resour. Res., 30(5): 1227-1239.

Unland, H.D., House, P.R., Shuttleworth, W.J., and Yang, Z-L, 1996. Surface flux measurement and modelling at a semiarid Sonoran desert site. J. Agric. For. Meteorol., 82: 119-153.
Weltz, M.A., Richie, J.C., and Fox, H.D., 1994. Comparison of laser and field measurements of vegetation height and canopy cover. Water Resour. Res., 30(5): 1311-1319.

Williams, M.D., 1996. Evapotranspiration in southeastern Arizona semi-arid watersheds: Walnut Gulch and Cienega Creek. M.S. Thesis, The University of Arizona, Tucson, USA. 178 pp. 